\title{
Usefulness of SS18-SSX antibody as a diagnostic marker for pulmonary metastatic synovial sarcoma
}

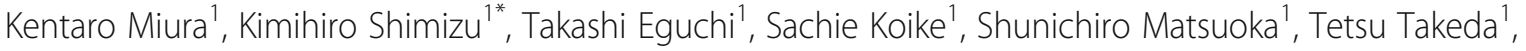 \\ Kazutoshi Hamanaka ${ }^{1}$ and Takeshi Uehara ${ }^{2}$
}

\begin{abstract}
Background: The novel SS18-SSX fusion-specific antibody is reported to have high sensitivity and specificity for the diagnosis of primary synovial sarcoma (SS), which often metastasizes to the lung. Thus far, no study has validated the diagnostic efficacy of SS18-SSX antibody for pulmonary metastatic SS. Therefore, we aimed to investigate the usefulness of the SS18-SSX antibody in the diagnosis of pulmonary metastatic SS.

Methods: We evaluated the immunohistochemistry of SS18-SSX fusion-specific antibody (E9X9V) in 10 pulmonary metastatic SS cases and the corresponding five primary sites (four limbs and one mediastinum) in five patients, for whom SS was already diagnosed and confirmed by fluorescence in-situ hybridization in the metastatic and primary sites, and in 93 clinical and histologic mimics including 49 non-SS, pulmonary metastatic sarcomas, 39 primary lung cancers, and five intrathoracic solitary fibrotic tumors. All specimens were surgically resected at Shinshu University Hospital during 2001-2019. For primary and metastatic SS, we also evaluated SS18-SSX immunohistochemistry using needle biopsy and touch imprint cytology specimens from the primary site.

Results: SS18-SSX staining was diffusely-strongly positive in all 10 pulmonary metastatic SS cases and the corresponding five primary sites; whereas, it was negative in all 93 clinical and histologic mimics (100\% sensitivity and 100\% specificity). Further, SS18-SSX staining was also sufficiently positive in the biopsy and cytology specimens.

Conclusions: Immunohistochemistry of the SS18-SSX fusion-specific antibody is useful for the differential diagnosis of pulmonary metastatic SS in clinical practice. This simple and reliable method has the potential to replace traditional genomic tests. However, further studies are warranted in this regard.
\end{abstract}

Keywords: Synovial sarcoma, SS18-SSX antibody, Immunohistochemistry, Pulmonary metastasis

\section{Background}

Synovial sarcoma (SS) is a malignant mesenchymal neoplasm with varying epithelial differentiation, and accounts for $5-10 \%$ of all soft tissue sarcomas [1-4]. SS frequently occurs in the limbs and occasionally in the chest cavity. Approximately 50\% of the patients with SS

\footnotetext{
* Correspondence: kmshimizu@gmail.com

${ }^{1}$ Division of General Thoracic Surgery, Department of Surgery, Shinshu University School of Medicine, Matsumoto, Japan

Full list of author information is available at the end of the article
}

experience metastasis, which is commonly observed in the lungs and pleura $[3,5]$. In patients with resectable pulmonary metastases of SS, the mainstay of treatment is pulmonary metastasectomy, which is reported to show good prognosis [6-8]. Several studies have reported that repeated pulmonary metastasectomies would be a feasible strategy for select patients with metastatic SS [9, 10]. Therefore, thoracic surgeons frequently encounter cases of pulmonary metastatic SS in clinical practice.

(c) The Author(s). 2021 Open Access This article is licensed under a Creative Commons Attribution 4.0 International License, which permits use, sharing, adaptation, distribution and reproduction in any medium or format, as long as you give appropriate credit to the original author(s) and the source, provide a link to the Creative Commons licence, and indicate if changes were made. The images or other third party material in this article are included in the article's Creative Commons licence, unless indicated otherwise in a credit line to the material. If material is not included in the article's Creative Commons licence and your intended use is not permitted by statutory regulation or exceeds the permitted use, you will need to obtain permission directly from the copyright holder. To view a copy of this licence, visit http://creativecommons.org/licenses/by/4.0/ The Creative Commons Public Domain Dedication waiver (http://creativecommons.org/publicdomain/zero/1.0/) applies to the data made available in this article, unless otherwise stated in a credit line to the data. 
A diagnosis of SS is made depending on the presence of the hallmark $t(X ; 18)(p 11 ; q 11)$ translocation, which is not found in other neoplasms $[4,11]$. This recurrent translocation results in the fusion of the SS18 gene on chromosome 18 with one of the several SSX genes on chromosome X (SSX1 in two-thirds of SS, SSX2 in onethird, and SSX4 rarely), which create SS18-SSX fusion oncogenes in $>95 \%$ of the cases $[4,11,12]$. Histologically, SS is divided into two major subtypes (biphasic type and monophasic spindle cell type) and other rarer subtypes (monophasic epithelial, poorly differentiated, calcifying/ossifying, and myxoid types) [3, 4]. Owing to the varying histological combinations of epithelioid and spindle cells, the differential diagnosis of SS widely ranges from non-SS bone and soft tissue sarcomas to various types of carcinomas. Therefore, making a definitive diagnosis of SS based only on histological findings is difficult, and genetic confirmation of the SS18-SSX fusion by fluorescence in situ hybridization (FISH) or reverse transcriptase-polymerase chain reaction (RT-PCR) has been the gold standard for the diagnosis of SS [3, 4]. However, these tests are not widely available because of their high cost and time-consuming process [13].

In patients with pulmonary metastatic SS, clinical course, radiologic features, and histologic findings are widely variable, resulting in difficulties in the differential diagnosis of SS from clinical and histologic mimics such as primary lung cancer and other bone/soft tissue sarcomas $[3,14,15]$. Particularly in cases of late and solitary pulmonary metastatic SS, the differential diagnosis would be difficult but clinically important. Therefore, a clinically useful and pathologically accurate test for the diagnosis of metastatic SS is warranted.

Recently, Baranov et al. proposed a novel diagnostic test for primary SS using immunohistochemistry (IHC) of the SSX-SS18 fusion-specific antibody, with high sensitivity (95\%) and specificity (100\%) [4]. However, it has not been clarified whether SS18-SSX IHC can be used as a marker to diagnose pulmonary metastatic SS, particularly during differential diagnosis from clinical and histologic mimics such as primary lung cancers and pulmonary metastatic non-SS sarcomas.

The present study aimed to evaluate the usefulness of SS18-SSX IHC in the diagnosis of pulmonary metastatic SS and the diagnosis of the rare mediastinum-originated SS and the potential utility of biopsy and/or cytology specimens for the IHC test.

\section{Methods}

\section{Study cohort and design}

We retrieved the details of patients with SS, who underwent surgical resection between 2001 and 2019, from the Pathology Department of Shinshu University Hospital. The whole slides of the tumor of five patients were available for 10 pulmonary metastatic SS and the corresponding five primary sites (four in the limbs and one mediastinum), and of 93 clinical and histologic mimics, including 49 pulmonary metastatic bone and soft tissue sarcomas other than SS (osteosarcoma, chondrosarcoma, liposarcoma, malignant fibrous histiocytoma, Ewing's sarcoma, leiomyosarcoma, fibrosarcoma, and undifferentiated pleomorphic sarcoma), 39 primary lung cancers (adenocarcinoma, squamous cell carcinoma, small cell lung cancer, large cell lung cancer, pleomorphic cell carcinoma, and carcinoid), and 5 intrathoracic solitary fibrotic tumors. All patients with SS underwent surgical resection of the primary origin and were diagnosed with SS by SS18 break-apart FISH to detect the SS18-SSX fusion gene. In metastatic SS specimens, two metastatic sites were selected from each patient, and a total of 10 specimens were stained. Chemotherapy had been initiated for all patients before the resection of the metastatic specimens. SS and other bone and soft tissue sarcomas were consecutive cases, including repeated pulmonary metastasectomies. Patients with SFT and primary lung cancer were randomly selected from our database. This study was approved by the Shinshu University Research Ethics Committee (No. 4870).

\section{Immunohistochemical staining}

IHC staining was performed by manual methods. Specimens of whole tumors (SS, other bone soft tissue sarcoma, primary lung cancer, and solitary fibrotic tumor [SFT]) were paraffin-embedded and cut into 4- $\mu \mathrm{m}$-thick sections. They were deparaffinized with ethanol and xylene, and endogenous peroxidase activity was blocked using methanol and $30 \% \mathrm{H}_{2} \mathrm{O}_{2}$ solution for $30 \mathrm{~min}$ at room temperature. Protein blocking was performed using $1 \%$ bovine serum albumin [BSA]/phosphate-buffered saline [PBS] for $1 \mathrm{~h}$ at room temperature. The sections were incubated overnight at $4{ }^{\circ} \mathrm{C}$ with primary antibody against human SS18-SSX (clone E9X9V, 1: 1000, Cell Signaling Technology, Danvers, MA, USA). The sections were washed in PBS three times and probed with an anti-rabbit IgG labeled with Histofine Simple Stain MAX-PO (Nichirei, Tokyo, Japan) for $1 \mathrm{~h}$ at room temperature. They were washed three times in PBS, and the immune complex was visualized using Histofine Simple Stain 3,3'-diaminobenzidine (Nichirei, Tokyo, Japan). After washing in water, the sections were counterstained with hematoxylin.

Immunostaining of intraoperative sealed cytology was performed similarly. The tumor was directly smeared onto the slide grass and then fixed with 99.5\% ethanol. The subsequent immunostaining steps were the same.

Immunoactivity was reviewed by one pathologist (UT) and one thoracic surgeon (MK). 


\section{Results}

\section{Characteristics of patients with synovial sarcoma}

The characteristics of patients with SS are presented in Table 1. All SS of primary origin and pulmonary metastasis had already been diagnosed using SS18 break-apart FISH. The age at the identification of the primary tumor as SS was considered for each patient. In all five patients with SS, at least two metachronous metastasectomies were performed. The duration between the resection of primary sites and pulmonary metastasectomies ranged from 28 to 108 months. Cases 1, 3, 4, and 5 were monophasic spindle cell types, and Case 2 was biphasic type.

In Case 1, a 63-year-old woman with primary SS in the left ankle underwent pulmonary metastasectomy three times. IHC of SS18-SSX for pulmonary metastases was obtained from the first and second metastasectomy specimens. Figure 1A shows the computed tomographic findings of solitary pulmonary metastasis in the left lower lobe before the initial left wedge resection in this case.

In Case 2, a 28-year-old man had primary SS in the mediastinum. The large mass $(60 \times 60 \times 40 \mathrm{~mm})$ was protruding from the left side chest cavity (Fig. 2A, B), which was resected with combined pericardial resection by median sternotomy. In this case, the definitive diagnosis of SS was not reached until the initial metastasectomy, which was 108 months after the primary surgery when SS was finally diagnosed through comprehensive pathology workups including SS18 break-apart FISH for primary and metastatic sites. Figure $2 \mathrm{C}$ shows FISH for SS18 rearrangement in the primary tissue, demonstrating a disconnected SS18 gene. No evidence of recurrence was observed 17 months after the last pulmonary metastasectomy.

In Case 3, a 33-year-old man with primary SS in the left forearm underwent pulmonary metastasectomy four times and subsequent radiation therapy for right-sided pulmonary metastasis. Figure $1 \mathrm{~B}$ shows the computed tomographic findings of the solitary pulmonary metastasis in the left lower lobe before left basal segmentectomy. IHC of SS18-SSX for pulmonary metastases was obtained from the first and second metastasectomy specimens.

In Case 4, a 51-year-old man had the primary origin as the left knee. He underwent pulmonary metastasectomy five times. The patient was followed up without any treatment. IHC of SS18-SSX for pulmonary metastases was obtained from the third and fourth metastasectomy specimens.

In Case 5, a 30-year-old man had the primary origin as the right forearm. He underwent pulmonary metastasectomies four times. IHC of SS18-SSX for pulmonary metastases was obtained from the second and third metastasectomy specimens. He had recurrence and was undergoing chemotherapy.

\section{IHC}

Figure 3 shows the histologic findings of SS18-SSX IHC and hematoxylin and eosin of 10 pulmonary metastatic SS and 5 corresponding primary sites from 5 patients with SS. The SS18-SSX fusion-specific antibody was positive with diffusely strong staining in all 10 metastatic SS samples. All five primary SS tumors were stained similarly to the corresponding metastatic SS. However,

Table 1 Characteristics of the five patients with synovial sarcoma who underwent pulmonary metastasectomy

\begin{tabular}{|c|c|c|c|c|c|c|c|c|c|c|}
\hline $\begin{array}{l}\text { Case } \\
\text { no. }\end{array}$ & $\begin{array}{l}\text { Age, } \\
\text { years }\end{array}$ & Sex & Primary & State & Type & $1 \mathrm{st}$ & 2nd & $3 r d$ & 4th & 5 th \\
\hline \multirow[t]{2}{*}{1} & 63 & $\mathrm{~F}$ & Ankle & Dead & Monophasic & $\begin{array}{l}\text { Left wedge } \\
\text { resection (1) }\end{array}$ & $\begin{array}{l}\text { Right wedge resection } \\
(2)\end{array}$ & $\begin{array}{l}\text { Left wedge } \\
\text { resection (1) }\end{array}$ & & \\
\hline & & & & & & 39 months & 59 months & 61 months & & \\
\hline \multirow[t]{2}{*}{2} & 28 & $M$ & Mediastinum & Alive & Biphasic & $\begin{array}{l}\text { Right lower } \\
\text { lobectomy (1) }\end{array}$ & $\begin{array}{l}\text { Left wedge resection + } \\
\text { chest wall resection }\end{array}$ & & & \\
\hline & & & & & & 108 months & 177 months & & & \\
\hline \multirow[t]{2}{*}{3} & 33 & $M$ & Forearm & Alive & Monophasic & $\begin{array}{l}\text { Right basal } \\
\text { segmentectomy } \\
\text { (1) }\end{array}$ & $\begin{array}{l}\text { Left wedge resection } \\
\text { (1) }\end{array}$ & $\begin{array}{l}\text { Left basal } \\
\text { segmentectomy } \\
\text { (1) }\end{array}$ & $\begin{array}{l}\text { Left wedge } \\
\text { resection (1) }\end{array}$ & \\
\hline & & & & & & 48 months & 63 months & 82 months & 100 months & \\
\hline \multirow[t]{2}{*}{4} & 51 & $M$ & Knee & Alive & Monophasic & $\begin{array}{l}\text { Right wedge } \\
\text { resection ( } 2)\end{array}$ & $\begin{array}{l}\text { Left wedge resection } \\
\text { (2) }\end{array}$ & $\begin{array}{l}\text { Right wedge } \\
\text { resection (1) }\end{array}$ & $\begin{array}{l}\text { Left wedge } \\
\text { resection (1) }\end{array}$ & $\begin{array}{l}\text { Right wedge } \\
\text { resection (1) }\end{array}$ \\
\hline & & & & & & 28 months & 59 months & 76 months & 97 months & 108 months \\
\hline \multirow[t]{2}{*}{5} & 30 & $M$ & Forearm & Alive & Monophasic & $\begin{array}{l}\text { Right wedge } \\
\text { resection (3) }\end{array}$ & $\begin{array}{l}\text { Left wedge resection } \\
\text { (2) }\end{array}$ & $\begin{array}{l}\text { Right wedge } \\
\text { resection (2) }\end{array}$ & $\begin{array}{l}\text { Left wedge } \\
\text { resection (3) }\end{array}$ & \\
\hline & & & & & & 32 months & 34 months & 68 months & 107 months & \\
\hline
\end{tabular}

The age at which the primary tumor was identified as SS was considered for each patient. The months listed below the operative procedure indicates the duration since the identification of the primary origin. The number in parentheses next to the surgical procedure indicates the number of resected tumors 

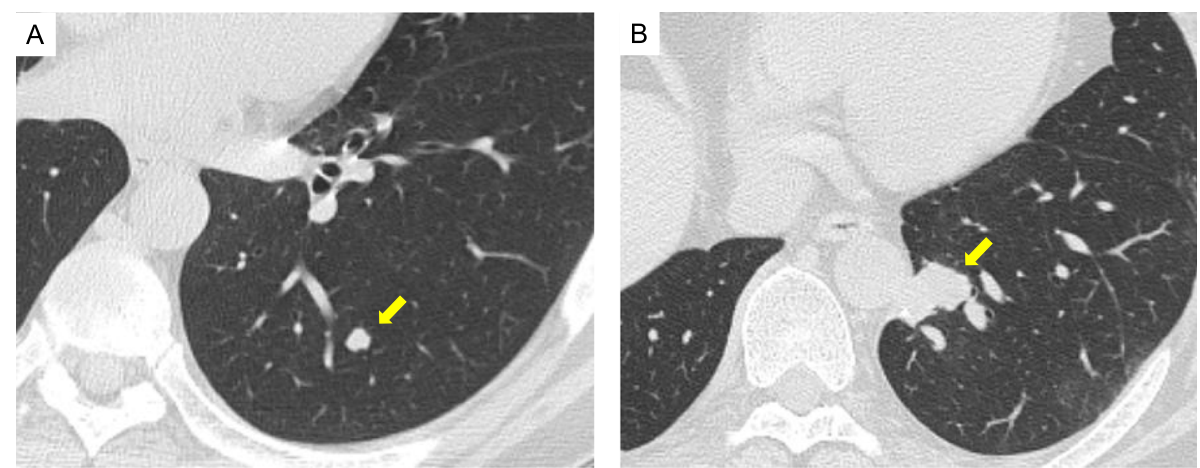

Fig. 1 Solitary pulmonary metastasis of synovial sarcoma (SS) in Case 1 (A) and Case 3 (B)

no staining of SS18-SSX was observed in the 93 clinical and histologic mimics (49 other bone and soft tissue sarcomas, 39 primary lung cancers, and 5 SFTs). Figure 4 shows the histologic findings of SS18-SSX IHC of 15 representative cases from 93 clinical and histological mimics. A summary of the IHC results is presented in Table 2.

Figure 5A shows the histologic finding of SS18-SSX IHC of a percutaneous needle biopsy specimen from the primary right forearm tumor in Case 5 , demonstrating diffuse strong staining of SS18-SSX antibody similar to the surgically resected specimen (Fig. 3T). Figure 5B shows the cytological findings of SS18-SSX IHC of intraoperative touch imprint cytology specimen from the pulmonary metastatic site, demonstrating strong staining of the SS18-SSX antibody.

\section{Discussion}

In this study, we demonstrated the usefulness of the IHC of SS18-SSX fusion-specific antibody for the differential diagnosis of pulmonary metastatic SS from clinical and histological mimics. The significant findings of this
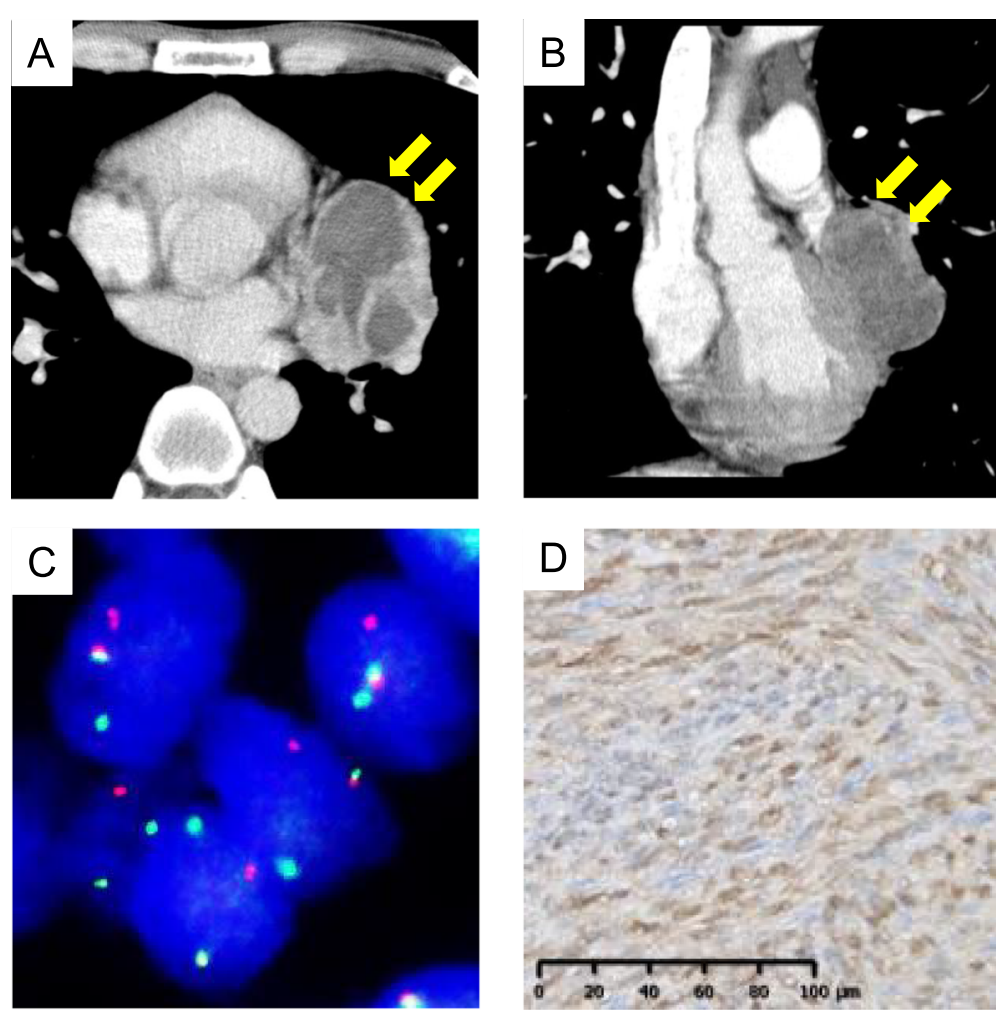

Fig. 2 Fluorescence in situ hybridization for SS18 rearrangement and immunostaining of SS18-SSX antibody in Case 2 (A)(B) The chest computed tomography (CT) scan shows a mediastinal mass of size $60 \times 60 \times 40 \mathrm{~mm}$. (C) Image showing the results of fluorescence in situ hybridization for SS18 rearrangement. A disconnected SS18 gene can be seen. (D) The SS18-SSX fusion-specific antibody (E9X9V) is positive 


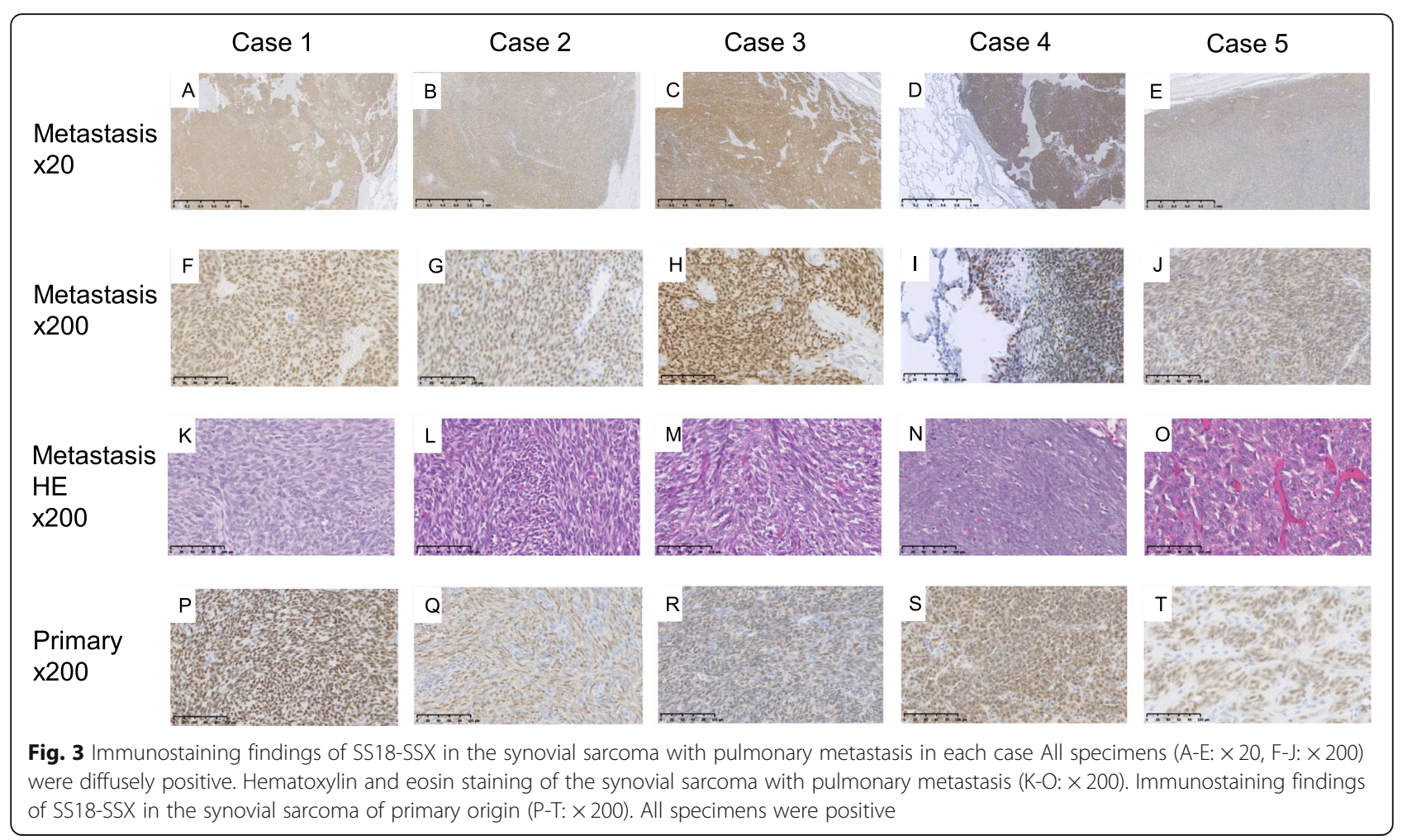

study are as follows: 1) this is the first study to validate the diagnostic performance of SS18-SSX IHC for the diagnosis of pulmonary metastatic SS; 2) we examined SS18-SSX IHC in clinical and histologic mimics of pulmonary metastatic SS, including various types of primary lung cancers and pulmonary metastatic non-SS sarcomas; 3 ) the sensitivity and specificity for the diagnosis of pulmonary metastatic SS were high (both 100\%); 4) positive SS18-SSX IHC was seen in the biopsy and cytology specimens, suggesting the usefulness of the test in clinical practice; 5) positive SS18-SSX IHC in a rare case of mediastinum-originated SS suggested a potential routine use of the test for the differential diagnosis of intrathoracic indeterminate sarcomas; and 6) the simple and widely prevalent IHC technique for the test with a high diagnostic performance could replace traditional genomic tests such as FISH or RT-PCR.

The standard test for the diagnosis of SS has been genomic tests to detect the SS18-SSX gene fusion by FISH or RT-PCR [13], which have reported to be highly specific tests. However, several studies suggested the relatively low sensitivity (83-94\%) of these techniques [16, 17] and their technical and costrelated issues [13]. Alternatively, IHC of transducinglike enhancer split 1 (TLE1) has been recognized to distinguish SS from other soft tissue malignancies [3, 18]. Although TLE1 is reported to show strong and diffuse nuclear staining in SS, the specificity of TLE1 IHC for the diagnosis of SS is low because of its positivity in up to one-third of non-SS sarcomas [3, 15, 19-21]. Recently, Baranov et al. evaluated SSXSS18 IHC in 100 genetically confirmed primary SS tumors and 300 histologic mimics of SS, demonstrating that SS18-SSX IHC had high sensitivity (95\%) and high specificity (100\%) for the diagnosis of primary SS and described that the test could replace traditional genomic tests based on its technical simplicity and high diagnostic performance [4]. No study investigated the diagnostic performance of the test for the diagnosis of metastatic SS to date and our current study is the first to validate the usefulness of SS18SSX IHC for the diagnosis of pulmonary metastatic SS, which demonstrated high sensitivity (100\%) and sensitivity (100\%) to distinguish SS from clinical and histologic mimics.

Our current study also provides supportive evidence to use SS18-SSX IHC for the differential diagnosis of indeterminate mediastinal sarcomas. Because of the rarity of primary mediastinal sarcomas including SS [22], the routine use of genetic tests for the differential diagnosis of SS would not be realistic in clinical practice. In case 2 , the definitive diagnosis of SS was not reached until the initial metastasectomy 108 months after the primary surgery when SS was suspected, and FISH was performed. In such cases, SS18-SSX IHC would be a better alternative option for differentiating SS because of its technical simplicity, relatively low cost, and good diagnostic performance. 

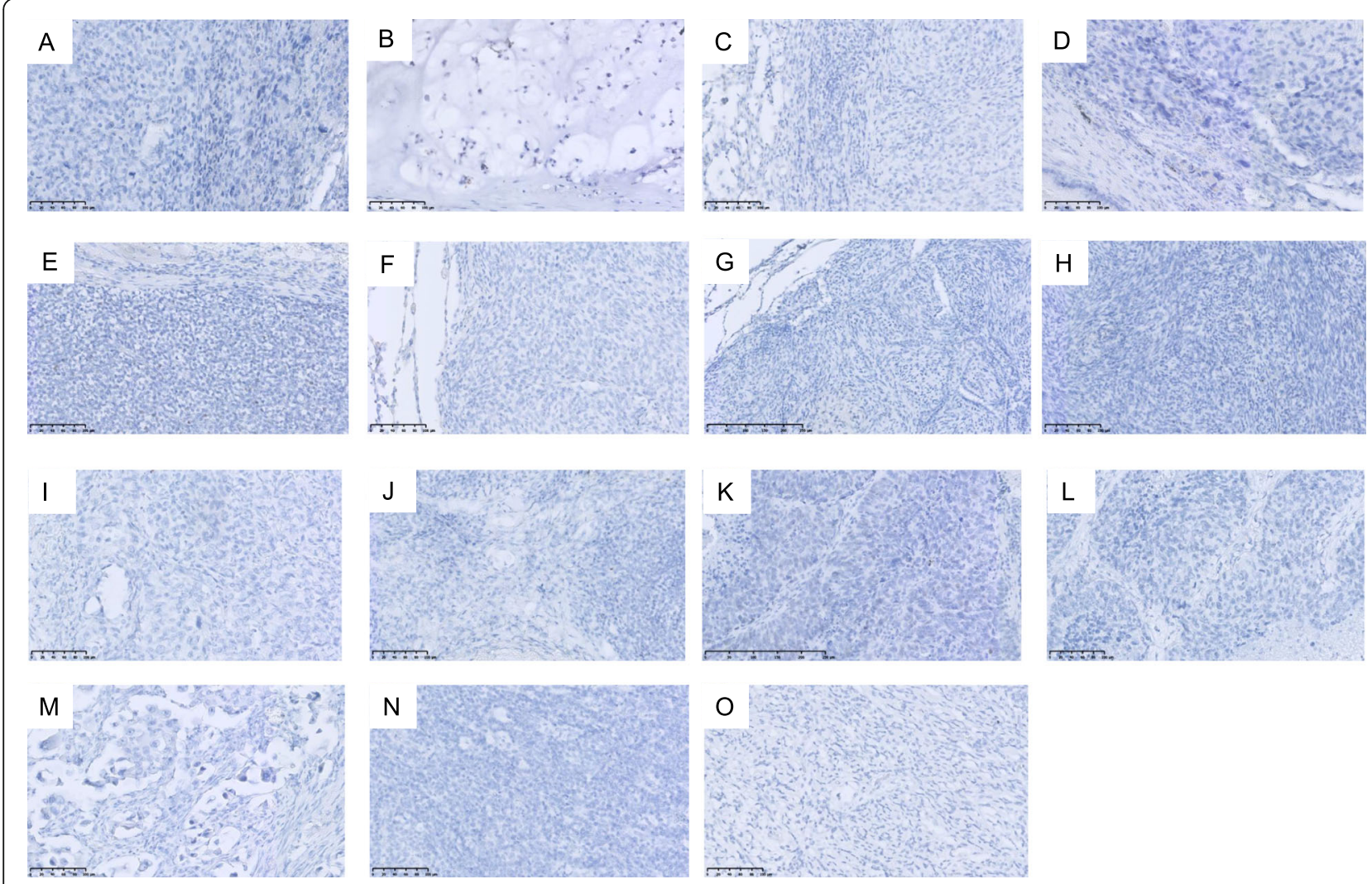

Fig. 4 Representative findings of immunostaining of SS18-SSX in other bone soft tissue sarcoma $(\times 200)(A)$ Osteosarcoma, (B) Chondrosarcoma, (C) Liposarcoma, (D) Malignant fibrous histiocytoma, (E) Ewing's sarcoma, (F) Fibrosarcoma, (G) Leiomyosarcoma, (H) Undifferentiated spindle cell sarcoma, (I) Adenocarcinoma, (J) Squamous cell carcinoma, (K) Small cell lung cancer, (L) Large cell lung cancer, (M) Pleomorphic carcinoma, (N)

Typical carcinoid, and $(\mathrm{O})$ Solitary fibrous tumor. All cases were negative

Table 2 Summary of the results of IHC staining for SS18-SSX antibody

\begin{tabular}{lll}
\hline & Number & SS18-SSX-positive ratio \\
\hline Synovial sarcoma (metastasis) & 10 & $100 \%$ \\
Synovial sarcoma (primary) & 5 & $100 \%$ \\
Non-SS pulmonary metastatic tumors & & \\
$\quad$ Osteosarcoma & 8 & $0 \%$ \\
Chondrosarcoma & 7 & $0 \%$ \\
Liposarcoma & 5 & $0 \%$ \\
Malignant fibrous histiocytoma & 9 & $0 \%$ \\
Ewing's sarcoma & 4 & $0 \%$ \\
Leiomyosarcoma & 9 & $0 \%$ \\
Fibrosarcoma & 3 & $0 \%$ \\
Undifferentiated pleomorphic sarcoma & 4 & $0 \%$ \\
Primary lung cancer & & \\
Adenocarcinoma & 9 & $0 \%$ \\
Squamous cell carcinoma & 5 & $0 \%$ \\
Small cell lung cancer & 4 & $0 \%$ \\
Large cell lung cancer & 5 & $0 \%$ \\
Pleomorphic carcinoma & 8 & $0 \%$ \\
Carcinoid & 8 & $0 \%$ \\
Solitary fibrous tumor & 5 & $0 \%$ \\
\hline
\end{tabular}

IHC immunohistochemistry, SS synovial sarcoma
More importantly, our current study suggests the potential utility of SS18-SSX IHC for biopsy and/or cytology specimens. In case 5, sufficient staining of SS18-SSX was confirmed by needle biopsy and touch imprint cytology specimens from the primary site of SS. Although SS18-SSX IHC in biopsy or cytology specimens from pulmonary metastatic SS was not assessed in this study, a differential diagnosis of SS could be made using small amounts of tumor tissue or cells obtained by bronchoscopy or imaging-guided biopsy.

The five primary and ten metastatic SS samples in this study were strongly positive for SS18-SSX IHC (100\% sensitivity). However, due to uncommon variants of SS18SSX fusion, the sensitivity of SS18-SSX IHC is not perfect $[4,23]$. Tahara et al. suggested RT-PCR and DNA sequencing would be useful to confirm the diagnosis in such cases [23]. Baranov et al., however, suggested that these cases could be recognized by the SSX C-terminus antibody (E5A2C), and therefore, the combination of these IHCs (SS18-SSX and SSX C-terminus) could be the gold standard of molecular genetic or cytogenetic testing in the majority of SS. SSX IHC should be considered in cases with a high suspicion of SS but negative for SS18-SSX. 

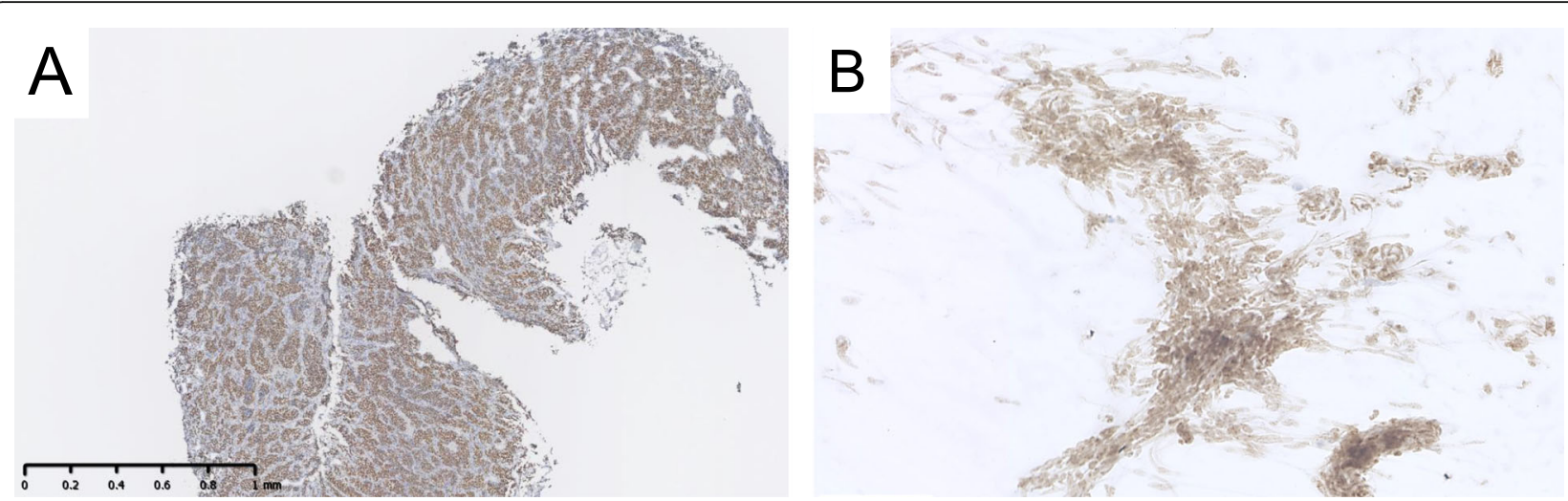

Fig. 5 SS18-SSX immunostaining in the synovial sarcoma: Case 5 (A); intraoperative sealed cytology: Case 3 (B). The image shows strong diffuse nuclear staining

This study had some limitations. First, the number of SS cases was small, and there were no cases with negative SS18-SSX IHC in the primary site of SS. Therefore, it is unknown whether metastatic sites in such cases could be identified using SS18-SSX IHC. Second, we only tested two selected metastatic sites in each SS case, which might have affected the results of this study. Third, we did not assess SS18-SSX IHC in a primary carcinosarcoma of the lung, which is an important differential diagnosis for SS.

\section{Conclusions}

In conclusion, we showed the usefulness of IHC of SS18-SSX fusion-specific antibody for the differential diagnosis of pulmonary metastatic SS from clinical/ histological mimics with high diagnostic performance (100\% sensitivity and 100\% specificity). We also showed the potential utility of SS18-SSX IHC for the diagnosis of SS arising from rare origins such as the mediastinum and SS obtained by biopsy/cytology specimens. This simple and reliable method could replace traditional genomic tests in terms of the differential diagnosis of pulmonary metastatic SS.

\section{Abbreviations}

SS: Synovial sarcoma; FISH: Fluorescence in situ hybridization; RTPCR: Reverse transcriptase-polymerase chain reaction; IHC: Immunohistochemistry; SFT: Solitary fibrotic tumor; BSA: Bovine serum albumin; PBS: Phosphate-buffered saline

\section{Acknowledgements}

We thank Masanobu Momose of the Department of Laboratory Medicine and Sachie Shimoeda of the Division of General Thoracic Surgery at Shinshu University School of Medicine for their technical assistance in immunohistochemistry analysis.

\section{Authors' contributions}

$\mathrm{KM}, \mathrm{KS}, \mathrm{TE}, \mathrm{SK}, \mathrm{SM}, \mathrm{T}$, and $\mathrm{KH}$ : surgical pulmonary resection, methodology, and data acquisition. KM and TU: evaluation of pathology. KM: drafted the manuscript. TE and KS reviewed the manuscript. KS: finalized the manuscript. All authors read and approved the final manuscript.
Funding

Not Applicable.

\section{Availability of data and materials}

The data presented in this study can be shared in response to reasonable request to the corresponding author.

\section{Declarations}

Ethics approval and consent to participate

This study was approved by the Shinshu University Research Ethics Committee (No. 4870).

Consent to Participate /Consent for Publication: All patients in this study consented to their involvement.

\section{Competing interests}

The authors declare that they have no competing interests.

\section{Author details}

'Division of General Thoracic Surgery, Department of Surgery, Shinshu University School of Medicine, Matsumoto, Japan. ${ }^{2}$ Department of Laboratory Medicine, Shinshu University School of Medicine, Matsumoto, Japan.

Received: 26 March 2021 Accepted: 27 May 2021

Published online: 14 June 2021

\section{References}

1. Shi W, Indelicato DJ, Morris CG, Scarborough MT, Gibbs CP, Zlotecki RA. Long-term treatment outcomes for patients with synovial sarcoma: a 40year experience at the University of Florida. Am J Clin Oncol. 2013;36(1):838. https://doi.org/10.1097/COC.0b013e31823fe450.

2. Sultan I, Rodriguez-Galindo C, Saab R, Yasir S, Casanova M, Ferrari A. Comparing children and adults with synovial sarcoma in the surveillance, epidemiology, and end results program, 1983 to 2005: an analysis of 1268 patients. Cancer. 2009;115(15):3537-47. https://doi.org/10.1002/cncr.24424.

3. Thway K, Fisher C. Synovial sarcoma: defining features and diagnostic evolution. Ann Diagn Pathol. 2014;18(6):369-80. https://doi.org/10.1016/j.a nndiagpath.2014.09.002.

4. Baranov E, McBride MJ, Bellizzi AM, Ligon AH, Fletcher CDM, Kadoch C, et al. A novel SS18-SSX fusion-specific antibody for the diagnosis of synovial sarcoma. Am J Surg Pathol. 2020;44(7):922-33. https://doi.org/10.1097/PAS. 0000000000001447 .

5. Bergh P, Meis-Kindblom JM, Gherlinzoni F, Berlin O, Bacchini P, Bertoni F, et al. Synovial sarcoma: identification of low and high risk groups. Cancer. 1999:85(12):2596-607. https://doi.org/10.1002/(SICl)1097-0142(1999061 5)85:12<2596::AID-CNCR16>3.0.CO;2-K.

6. Stanelle EJ, Christison-Lagay ER, Wolden SL, Meyers PA, La Quaglia MP. Pulmonary metastasectomy in pediatric/adolescent patients with synovial sarcoma: an institutional review. J Pediatr Surg. 2013:48(4):757-63. https:// doi.org/10.1016/j.jpedsurg.2012.09.042. 
7. Predina JD, Puc MM, Bergey MR, Sonnad SS, Kucharczuk JC, Staddon A, et al. Improved survival after pulmonary metastasectomy for soft tissue sarcoma. J Thorac Oncol. 2011;6(5):913-9. https://doi.org/10.1097/JTO.0b013 e3182106f5c.

8. Spillane AJ, A'Hern R, Judson IR, Fisher C, Thomas JM. Synovial sarcoma: a clinicopathologic, staging, and prognostic assessment. J Clin Oncol. 2000; 18(22):3794-803. https://doi.org/10.1200/JCO.2000.18.22.3794.

9. Lee K, Kang MC, Lee HW, Park JH, Baek HJ, Cho SJ, et al. Pulmonary metastasectomy in adult patients with synovial sarcoma: a single-center experience. Korean J Thorac Cardiovasc Surg. 2016;49(6):451-5. https://doi. org/10.5090/kjtcs.2016.49.6.451.

10. Yamamoto Y, Kanzaki R, Kanou T, Ose N, Funaki S, Shintani Y, et al. Longterm outcomes and prognostic factors of pulmonary metastasectomy for osteosarcoma and soft tissue sarcoma. Int J Clin Oncol. 2019;24(7):863-70. https://doi.org/10.1007/s10147-019-01422-0.

11. dos Santos NR, de Bruijn DR, van Kessel AG. Molecular mechanisms underlying human synovial sarcoma development. Genes Chromosom Cancer. 2001;30(1):1-14. https://doi.org/10.1002/1098-2264(2000)9999: 9999<::AID-GCC1056>3.0.CO;2-G.

12. Ladanyi M, Antonescu CR, Leung DH, Woodruff JM, Kawai A, Healey JH, et al. Impact of SYT-SSX fusion type on the clinical behavior of synovial sarcoma: a multi-institutional retrospective study of 243 patients. Cancer Res. 2002;62(1):135-40

13. Zaborowski M, Vargas AC, Pulvers J, Clarkson A, de Guzman D, Sioson L, et al. When used together SS18-SSX fusion-specific and SSX C-terminus immunohistochemistry are highly specific and sensitive for the diagnosis of synovial sarcoma and can replace FISH or molecular testing in most cases. Histopathology. 2020;77(4):588-600. https://doi.org/10.1111/his.14190.

14. Miettinen M, Limon J, Niezabitowski A, Lasota J. Calretinin and other mesothelioma markers in synovial sarcoma: analysis of antigenic similarities and differences with malignant mesothelioma. Am J Surg Pathol. 2001;25(5): 610-7. https://doi.org/10.1097/00000478-200105000-00007.

15. Kosemehmetoglu K, Vrana JA, Folpe AL. TLE1 expression is not specific for synovial sarcoma: a whole section study of 163 soft tissue and bone neoplasms. Mod Pathol. 2009;22(7):872-8. https://doi.org/10.1038/modpa thol.2009.47.

16. Ten Heuvel SE, Hoekstra HJ, Suurmeijer AJ. Diagnostic accuracy of FISH and RT-PCR in 50 routinely processed synovial sarcomas. Appl Immunohistochem Mol Morphol. 2008;16(3):246-50. https://doi.org/10.1097/ PAl.0b013e31815349f5.

17. Vargas AC, Selinger C, Satgunaseelan L, Cooper WA, Gupta R, Stalley P, et al. FISH analysis of selected soft tissue tumors: diagnostic experience in a tertiary center. Asia Pac J Clin Oncol. 2019;15(1):38-47. https://doi.org/1 0.1111/ajco.12980.

18. Jagdis A, Rubin BP, Tubbs RR, Pacheco M, Nielsen TO. Prospective evaluation of TLE1 as a diagnostic immunohistochemical marker in synovial sarcoma. Am J Surg Pathol. 2009;33(12):1743-51. https://doi.org/10.1097/PA S.0b013e3181b7ed36.

19. Valente AL, Tull J, Zhang S. Specificity of TLE1 expression in unclassified high-grade sarcomas for the diagnosis of synovial sarcoma. Appl Immunohistochem Mol Morphol. 2013;21(5):408-13. https://doi.org/10.1097/ PAl.0b013e318279f9ee.

20. Foo WC, Cruise MW, Wick MR, Hornick JL. Immunohistochemical staining for TLE1 distinguishes synovial sarcoma from histologic mimics. Am J Clin Pathol. 2011;135(6):839-44. https://doi.org/10.1309/AJCP45SSNAOPXYXU.

21. Matsuyama A, Hisaoka M, Iwasaki M, Iwashita M, Hisanaga S, Hashimoto H. TLE1 expression in malignant mesothelioma. Virchows Arch. 2010;457(5): 577-83. https://doi.org/10.1007/s00428-010-0975-8

22. Hartel PH, Fanburg-Smith JC, Frazier AA, Galvin JR, Lichy JH, Shilo K, et al. Primary pulmonary and mediastinal synovial sarcoma: a clinicopathologic study of 60 cases and comparison with five prior series. Mod Pathol. 2007; 20(7):760-9. https://doi.org/10.1038/modpathol.3800795.

23. Tahara S, Kohara M, Honma K, Morii E. Detection of synovial sarcoma with an atypical fusion transcript by using SS18-SSX and SSX antibodies. Pathol Int. 2020;70(9):689-91. https://doi.org/10.1111/pin.12976.

\section{Publisher's Note}

Springer Nature remains neutral with regard to jurisdictional claims in published maps and institutional affiliations.

\section{Ready to submit your research? Choose BMC and benefit from}

- fast, convenient online submission

- thorough peer review by experienced researchers in your field

- rapid publication on acceptance

- support for research data, including large and complex data types

- gold Open Access which fosters wider collaboration and increased citations

- maximum visibility for your research: over $100 \mathrm{M}$ website views per year

At $\mathrm{BMC}$, research is always in progress.

Learn more biomedcentral.com/submissions 